\title{
Short term effect of continuous positive airway pressure on muscle sympathetic nerve activity in patients with chronic heart failure
}

\author{
S Heindl, C Dodt, M Krahwinkel, G Hasenfuss, S Andreas
}

\begin{abstract}
Objective-To test the hypothesis that the short term application of continuous positive airways pressure (CPAP) increases muscle sympathetic nerve activity in patients with congestive heart failure.

Setting-University hospital and tertiary referral centre.

Patients-10 patients with congestive heart failure (New York Heart Association functional class III; mean (SEM) left ventricular ejection fraction $22(1) \%)$ and 10 healthy subjects matched for age, sex, and weight.

Main outcome measurements-Muscle sympathetic nerve activity, assessed by microneurography of the peroneal nerve, blood pressure, heart rate, minute ventilation, transcutaneous oxygen saturation, and end tidal $\mathrm{PCO}_{2}$ were measured during normal breathing, mask breathing, and CPAP at 5 and $10 \mathrm{~cm} \mathrm{H}_{2} \mathrm{O}$.

Results-CPAP induced an increase in muscle sympathetic nerve activity and blood pressure in both the patients and the control subjects. In the patients, sympathetic nerve activity increased from 43 (14) bursts/min during mask breathing to 47 (13) bursts/min at CPAP $10 \mathrm{~cm} \mathrm{H}_{2} 0$ $(\mathrm{p}=0.03)$; mean blood pressure increased from 80 (3) $\mathrm{mm} \mathrm{Hg}$ to 86 (4) $\mathrm{mm} \mathrm{Hg}(\mathrm{p}<0.001)$. Oxygen saturation improved during CPAP in the patients, from $95.7(0.6) \%$ to $96.6(0.7) \%$ $(\mathrm{p}=0.004)$ and remained stable in the control group. There was no effect of CPAP on minute ventilation or heart rate.
\end{abstract}

Conclusions-In patients with congestive heart failure, short term CPAP elicits sympathetic activation, probably because of unloading of the aortic or cardiopulmonary baroreceptors.

(Heart 2001;85:185-190)

Keywords: heart failure; sympathetic activation; continuous positive airways pressure

Congestive heart failure is an important cause of morbidity and mortality, with limited treatment available. The detrimental role of dysregulation of the autonomic nervous system in congestive heart failure, characterised by sympathetic activation and vagal withdrawal, has been clearly established. ${ }^{12}$ Concomitant Cheyne-Stokes respiration has been recognised as a sign of poor prognosis, raising the question of the appropriate treatment for this autonomic disturbance. ${ }^{34}$

Continuous positive airways pressure (CPAP) has been reported to improve cardiac output in acute cardiogenic pulmonary

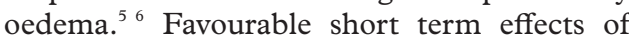
CPAP have also been described in patients with stable congestive heart failure and raised pulmonary capillary wedge pressure. ${ }^{78}$ There is debate about the effectiveness of CPAP for the treatment of congestive heart failure and concomitant Cheyne-Stokes respiration. While Naughton and colleagues reported an improvement of left ventricular ejection fraction and a reduction in Cheyne-Stokes respiration while on long term $\mathrm{CPAP},{ }^{9}$ other investigators have not found favourable effects of CPAP in patients with congestive heart failure and Cheyne-Stokes respiration. ${ }^{10-12}$

The improvement in left ventricular function in patients with congestive heart failure during short term application of CPAP has been attributed to increased intrathoracic pressure and reduced left ventricular transmural pressure, an index of afterload. ${ }^{9}$ In addition to these haemodynamic effects, it has been suggested that the short term application of CPAP increases heart rate variability and may improve the altered autonomic control of heart rate and cardiac function in congestive heart failure. ${ }^{13}$ However, increased intrathoracic pressure causes unloading of the aortic or cardiopulmonary baroreceptors and results in increased sympathetic activity. ${ }^{14}$

Our aim in this study was to investigate the short term effects of nasal CPAP on the sympathetic nervous system by microneurography of the peroneal nerve in patients with congestive heart failure and in healthy subjects. Our objective was to test the hypothesis that the short term application of CPAP would increase sympathetic activity in patients with congestive heart failure.

\section{Methods}

SUBJECTS

Patients with congestive heart failure and healthy control subjects were included in our study. Patients with moderate to severe congestive heart failure were eligible if they met the following criteria: age 19-75 years, left ventricular ejection fraction $<35 \%$ (gated blood pool), and in stable condition (no rales on auscultation or tibial oedema) on standard cardiac drugs (diuretics, angiotensin converting enzyme (ACE) inhibitors, and glycosides). Patients with congestive heart failure caused by valve disease or those on treatment with 
substances which directly influence the sympathetic nervous system ( $\beta$ blockers, central sympathoinhibitory agents) were excluded. Further exclusion criteria were myocardial infarction or pulmonary oedema within six months of entry, significant obstructive lung disease as defined by forced expiratory volume in one second or forced vital capacity $<65 \%$ of expected, obesity (body mass index $>28$ ), or a history of obstructive sleep apnoea. We also studied an equal number of control subjects matched for age, sex, and body mass index. We obtained a brief history and performed a physical examination, an ECG, and lung function tests on each control subject. All subjects were healthy non-smokers, and none was on regular drug treatment.

The study was approved by the local ethics committee. Informed written consent was obtained from all patients and control subjects.

MEASUREMENTS

Sympathetic activity was measured using microneurographic recordings of efferent muscle sympathetic nerve activity in the peroneal nerve. This reflects sympathetic discharge to the vascular bed of the skeletal muscle $e^{15}{ }^{16}$ and correlates well with plasma noradrenaline (norepinephrine) concentrations and noradrenaline spillover. ${ }^{17}$

After mapping the course of the peroneal nerve around the head of the fibula by transcutaneous electrical stimulation (Stimuplex HNS 11, B Braun, Melsungen, Germany), a tungsten microelectrode (shaft diameter $200 \mu \mathrm{m}$ and tip of $1-5 \mu \mathrm{m}$ ) was inserted into the nerve. A reference electrode was inserted subcutaneously $3 \mathrm{~cm}$ away. The nerve signals underwent amplification (50 000 times), bandpass filtering (band width of 700-2000 Hz), and passage through a resistance-capacitance integrating network with a time constant of 0.1 second, providing a mean voltage display of sympathetic nerve activity (Nerve Traffic Analysis System, model 662C-3, University of Iowa, Iowa City, USA). The procedure and the criteria for a satisfactory recording of muscle sympathetic nerve activity have been described previously. ${ }^{15}{ }^{16}$ Sympathetic bursts were identified by inspection of the mean voltage neurogram and quantified as bursts/minute and total activity (total burst amplitude/minute expressed as arbitrary units).

We recorded respiratory rate and tidal volume by respiration inductive plethysmography (Respitrace Systems, Ambulatory Monitoring Inc, New York, USA), which allows monitoring of respiration without the use of a mouthpiece. Thoracic and abdominal motions that occur with breathing cause changes in the oscillating frequency of circuits within the electronic system of the inductive plethysmograph transducer coils positioned around the rib cage and abdomen. These frequency changes are demodulated to produce output voltage signals. After calibration for volume, the summation signal reflects tidal volume. ${ }^{18}$

Heart rate was derived from a continuous recording of the ECG by surface electrodes on the chest. Blood pressure was measured non-invasively by sphygmomanometry (Dinamap XL Monitor, Model 9302, Johnson and Johnson Medical, Arlington, Texas, USA). Arterial oxygen saturation was measured transcutaneously on the tip of the index finger by pulse oximetry (Microspan 3040G, Biochem Int, Wanheshee, Winsconsin, USA), while the end tidal $\mathrm{PCO}_{2}$ was monitored continuously by withdrawing expired gas from the nostrils (Datex Normocap, Helsinki, Finland). In the absence of significant obstructive lung disease, the end tidal $\mathrm{CO}_{2}$ partial pressure correlates closely with arterial $\mathrm{CO}_{2}$ partial pressure. ${ }^{19}$

The mean voltage neurogram, ECG, and respiratory movements were continuously recorded with a paper chart recorder for further manual analysis.

\section{PROTOCOL}

Patients and control subjects were studied in the morning, two hours after a low energy breakfast free of beverages containing caffeine. Patients were asked to take their usual drugs except for diuretics, which were withheld on the morning of the study. Before the experiment was begun, patients and control subjects were placed in a supine position and familiarised with breathing through a nasal mask with and without the application of CPAP. After placement of the Respibands around the rib cage and abdomen, calibration of the Respitrace system was performed. The microelectrodes for nerve recordings, the ECG electrodes, the blood pressure cuff, and the sensors for $\mathrm{O}_{2}$ and $\mathrm{CO}_{2}$ measurement were positioned. After a satisfactory nerve signal had been obtained, the protocol started with a 20 minute recording period without a mask (baseline). An open mask with a $3 \mathrm{~cm}$ lumen of negligible resistance was then placed over each subject's nose with the mouth closed for 20 minutes (mask breathing/CPAP $0 \mathrm{~cm} \mathrm{H} \mathrm{H}_{2} \mathrm{O}$ ). Afterwards, CPAP 5 and $10 \mathrm{~cm} \mathrm{H}_{2} \mathrm{O}$ were consecutively applied for 20 minutes over the nasal mask, followed by a 20 minute recovery period without CPAP or mask.

\section{DATA ANALYSIS}

Data were analysed during the last five minutes of each period, and values for muscle sympathetic nerve activity, heart rate, systolic and diastolic pressures, tidal volume, respiratory rate, oxygen saturation, and end tidal $\mathrm{CO}_{2}$ were averaged over this time. The person interpreting the muscle sympathetic nerve activity recordings was blinded as to whether the subjects were patients or controls and which level of CPAP was used. All variables are given as mean (SEM). Demographic data and baseline values in patients and control subjects were compared with the two tailed paired Student $t$ test. Two way repeated measure analysis of variance (ANOVA) was used to analyse the differences in muscle sympathetic nerve activity, blood pressure, ventilation, and blood gases during mask breathing and CPAP; when ANOVA revealed significance, we performed the paired Student $t$ test and the Bonferroni procedure. Differences in the patients and control subjects are given as percentages referred to the values of mask breathing and 
Table 1 Demographics and baseline values in patients and control subjects

\begin{tabular}{lll}
\hline & $\begin{array}{l}\text { Patients } \\
(n=10)\end{array}$ & $\begin{array}{l}\text { Controls } \\
(n=10)\end{array}$ \\
\hline Age (years) & $55(4)$ & $55(4)$ \\
Body mass index $\left(\mathrm{kg} / \mathrm{m}^{2}\right)$ & $25(1)$ & $25(1)$ \\
Vital capacity (\% predicted) & $89(6)$ & $100(6)$ \\
FEV $_{1}$ (\% VC) & $78(3)$ & $85(5)$ \\
Total lung capacity (\% predicted) & $99(5)$ & $108(3)$ \\
MSNA (bursts/min) & $43(4)^{\star}$ & $30(5)$ \\
MSNA/TA (au) & $417(30)^{\star}$ & $265(69)$ \\
Heart rate (beats/min) & $64(2)$ & $62(2)$ \\
Mean blood pressure (mm Hg) & $80(4)^{\star}$ & $95(4)$ \\
Respiratory rate (breaths/min) & $16(1)$ & $14(1)$ \\
Tidal volume (ml) & $447(40)$ & $423(62)$ \\
Oxygen saturation (\%) & $95.5(0.3)$ & $96.0(0.5)$ \\
PCO (kPa) & $4.80(0.13)$ & $5.06(0.13)$ \\
\hline
\end{tabular}

Values are mean (SEM).

${ }^{\star} \mathrm{p}<0.05 v$ control subjects (paired $t$ test).

au, arbitrary units; $\mathrm{FEV}_{1}$, forced expiratory volume in one second; MSNA, muscle sympathetic nerve activity; $\mathrm{PCO}_{2}$, partial pressure of carbon dioxide; TA, total activity; VC, vital capacity.

were compared using the paired Student $t$ test. Statistical analyses were performed on a personal computer using StatView (Abacus, Berkeley, California, USA). Significance was accepted at a probability value of $\mathrm{p}<0.05$.

\section{Results}

SUBJECT CHARACTERISTICS

The characteristics of the 10 patients and the 10 healthy subjects are shown in table 1 . All patients were symptomatic (New York Heart Association functional class III). Two patients and two control subjects were women. Mean (SEM) left atrial diameter was 45 (2) $\mathrm{mm}$, left ventricular end diastolic diameter 69 (2) $\mathrm{mm}$, and left ventricular ejection fraction $22(1) \%$ in the patient group. Five patients had coronary artery disease and five had idiopathic dilated cardiomyopathy. Two patients had atrial fibrillation. A cardioverter-defibrillator had been implanted in three patients because of sustained ventricular tachycardia or ventricular fibrillation. Drugs consisted of an ACE inhibitor in 10 patients, a diuretic in eight, $\beta$ acetyldigoxin in seven, nitrates in six, and calcium antagonists in two.

Patients and control subjects did not differ in baseline values of heart rate, ventilation, blood gases, and lung function (table 1). Baseline values of muscle sympathetic nerve activity, expressed as bursts/min and total activity, were higher in the patient group than in the control group.
MASK BREATHING (CPAP $0 \mathrm{CM} \mathrm{H}_{2} \mathrm{O}$ )

Patients had a higher tidal volume during mask breathing than at baseline, at 447 (128) $v 545$ (179) $\mathrm{ml}(\mathrm{p}=0.003)$. In the control group, breathing with a nasal mask resulted in higher tidal volume (438 (54) v 536 (61) ml; $\mathrm{p}=0.002)$ as well as a higher oxygen saturation $(96(0.5) \% v 97.3(0.3) \% ; \mathrm{p}=0.02)$ and $\mathrm{a}$ higher partial pressure of $\mathrm{CO}_{2}(5.05(0.13) v$ $5.19(0.13) \mathrm{kPa} ; \mathrm{p}=0.001)$ when compared with normal breathing. Breathing with a nasal mask did not influence muscle sympathetic nerve activity, heart rate, or systolic, diastolic, and mean blood pressure in either group, nor did it affect the partial pressure of $\mathrm{CO}_{2}$ and oxygen saturation in the patient group. Thus any change in these variables during the application of CPAP is compared with mask breathing without CPAP in further analyses (table 2).

EFFECT OF CPAP ON MUSCLE SYMPATHETIC ACTIVITY, BLOOD PRESSURE, AND HEART RATE In both patients and control subjects, there was an increase in muscle sympathetic nerve activity while they were on CPAP, expressed either as bursts/min or as total activity (ANOVA, table 2). The relative increase in muscle sympathetic nerve activity did not differ significantly between the patient and control groups (table 3 ). The individual changes in muscle sympathetic nerve activity with CPAP in the patients and control subjects are shown in figs 1 and 2. In eight patients, CPAP at $10 \mathrm{~cm} \mathrm{H} \mathrm{H}_{2} \mathrm{O}$ increased the number of bursts/ min in a range from $2.2 \%$ to $57.7 \%$ compared with mask breathing. Two patients had a decrease in sympathetic nerve activity while on CPAP $10 \mathrm{~cm} \mathrm{H}_{2} \mathrm{O}(-4.5 \%$ and $-9 \%)$. These two patients did not differ at baseline from the others in sympathetic nerve activity, blood pressure, heart rate, underlying cardiac rhythm, cardiac dimensions, or oxygen saturation. However, they showed a different breathing pattern at baseline, characterised by a high respiratory rate and a low tidal volume, which was completely reversed by CPAP: respiratory rate decreased from 18 (1) breaths $/ \mathrm{min}$ at baseline to 11 (1) breaths/min at $10 \mathrm{~cm} \mathrm{H}_{2} \mathrm{O}$ CPAP, while tidal volume increased from 430 (48) $\mathrm{ml}$ at baseline to 712 (45) $\mathrm{ml}$ (compare with the values for the whole patient group in tables 1 and 2).

In the patients, both systolic and diastolic blood pressure increased during CPAP, while

Table 2 Effect of CPAP 0, 5, and $10 \mathrm{~cm} \mathrm{H}_{2} \mathrm{O}$ on muscle sympathetic nerve activity, blood pressure, and ventilation

\begin{tabular}{|c|c|c|c|c|c|c|c|c|}
\hline & \multicolumn{4}{|c|}{ Patients $(n=10)$} & \multicolumn{4}{|c|}{ Controls $(n=10)$} \\
\hline & CPAP $O$ & CPAP 5 & CPAP 10 & $\begin{array}{l}p \text { Value } \\
(\text { ANOVA })\end{array}$ & CPAP $O$ & CPAP 5 & CPAP 10 & $\begin{array}{l}p \text { Value } \\
(\text { ANOVA })\end{array}$ \\
\hline MSNA (bursts/min) & $43(14)$ & $45(13)$ & $47(13)^{\star}$ & 0.03 & $30(5)$ & $32(6)$ & $35(6)^{\star} \dagger$ & $<0.001$ \\
\hline MSNA/TA (au) & $349(48)$ & $411(53)^{\star}$ & $425(44)$ & 0.04 & $338(79)$ & $372(90)$ & $419(104)^{\star}$ & 0.02 \\
\hline Heart rate (beats/min) & $64(7)$ & $64(7)$ & $64(7)$ & NS & $62(2)$ & $63(2)$ & $64(2)$ & NS \\
\hline Systolic BP (mm Hg) & $110(17)$ & $114(22)$ & $115(20)^{\star}$ & 0.04 & $130(6)$ & $129(6)$ & $133(6)$ & NS \\
\hline Diastolic BP (mm Hg) & $65(8)$ & $70(11)^{\star}$ & $72(10)^{\star}$ & $<0.001$ & $79(3)$ & $79(3)$ & $83(3)^{\star}+$ & $<0.001$ \\
\hline Respiratory rate (breaths/min) & $15(5)$ & $13(4)$ & $13(2)$ & NS & $12(1)$ & $12(1)$ & $12(1)$ & NS \\
\hline Tidal volume $(\mathrm{ml})$ & $545(179)$ & $536(173)$ & $535(154)$ & NS & $536(61)$ & $525(79)$ & $648(118)$ & NS \\
\hline $\mathrm{PCO}_{2}(\mathrm{kPa})$ & $4.93(0.53)$ & $4.53(0.67)^{\star}$ & $4.27(0.80)^{\star} \dagger$ & $<0.001$ & $5.20(0.13)$ & $4.93(0.13)^{\star}$ & $4.53(0.27)^{\star}$ & 0.007 \\
\hline Oxygen saturation (\%) & $95.7(0.6)$ & $96.4(0.4)^{\star}$ & $96.6(0.7)^{\star}$ & 0.004 & $97.3(0.3)$ & $97.4(0.3)$ & $97.5(0.3)$ & NS \\
\hline
\end{tabular}

Values are mean (SEM).

${ }^{\star} \mathrm{p}<0.05 v$ CPAP 0 (paired $t$ test); $\nmid \mathrm{p}<0.05 v$ CPAP 5 (paired $t$ test).

$\mathrm{au}$, arbitrary units; $\mathrm{BP}$, blood pressure; MSNA muscle sympathetic nerve activity; $\mathrm{PCO}_{2}$, partial pressure of carbon dioxide; TA, total activity. 
Table 3 Comparison of CPAP induced changes in patient and control groups

\begin{tabular}{lll}
\hline & Patients $(n=10)$ & Controls $(n=10)$ \\
\hline MSNA (\%) & $12(6)$ & $20(5)$ \\
Mean blood pressure (\%) & $7(1)$ & $4(2)$ \\
Oxygen saturation (\%) & $1.1(0.3)$ & $0.3(0.2)^{\star}$ \\
$\mathrm{PcO}_{2}(\%)$ & $-12(3)$ & $-13(5)$ \\
\hline
\end{tabular}

Values are mean (SEM)

${ }^{\star} \mathrm{p}<0.05$ (paired $t$ test).

$(\%)=\left(\right.$ CPAP $\left.10 \mathrm{~cm} \mathrm{H}_{2} \mathrm{O}-\mathrm{CPAP} 0 \mathrm{~cm} \mathrm{H}_{2} \mathrm{O}\right) / \mathrm{CPAP} 0 \mathrm{~cm} \mathrm{H}_{2} \mathrm{O}$ $\times 100$.

MSNA, muscle sympathetic nerve activity; $\mathrm{PCO}_{2}$, partial pressure of carbon dioxide.

there was a significant increase only in diastolic blood pressure in the control subjects (ANOVA, table 2). Mean blood pressure increased significantly in both groups during CPAP $10 \mathrm{~cm} \mathrm{H}_{2} \mathrm{O}$ compared with mask breathing (80 (3) $v 86$ (4) $\mathrm{mm} \mathrm{Hg}, \mathrm{p}=0.0009$ in the patients; 96 (4) $v$ 100 (4) $\mathrm{mm} \mathrm{Hg}, \mathrm{p}=0.009$ in the control subjects; ANOVA). CPAP induced no change in heart rate in either group.

\section{EFFECT OF CPAP ON VENTILATION AND BLOOD} GASES

There was no significant change in respiratory rate or tidal volume in patients and control subjects while on CPAP compared with mask breathing (ANOVA, table 2). The partial pressure of $\mathrm{CO}_{2}$ was lower during CPAP 5 and $10 \mathrm{~cm} \mathrm{H}_{2} \mathrm{O}$ than during mask breathing in both groups. Oxygen saturation improved dur-

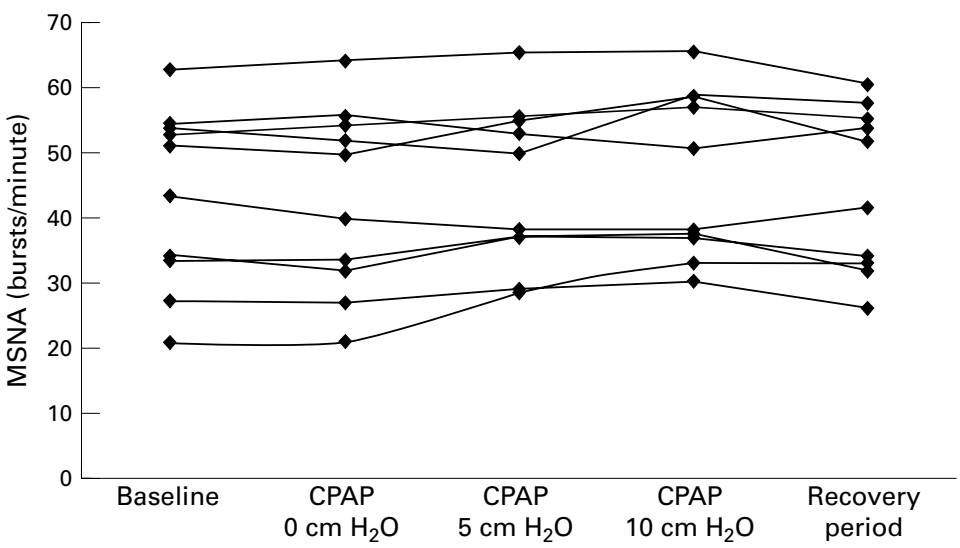

Figure 1 Individual changes of muscle sympathetic nerve activity (MSNA) at baseline, during mask breathing (CPAP $\left.0 \mathrm{~cm} \mathrm{H} \mathrm{H}_{2} \mathrm{O}\right)$, during $\mathrm{CPAP} 5$ and $10 \mathrm{~cm} \mathrm{H}_{2} \mathrm{O}$, and during the recovery period in the patients.

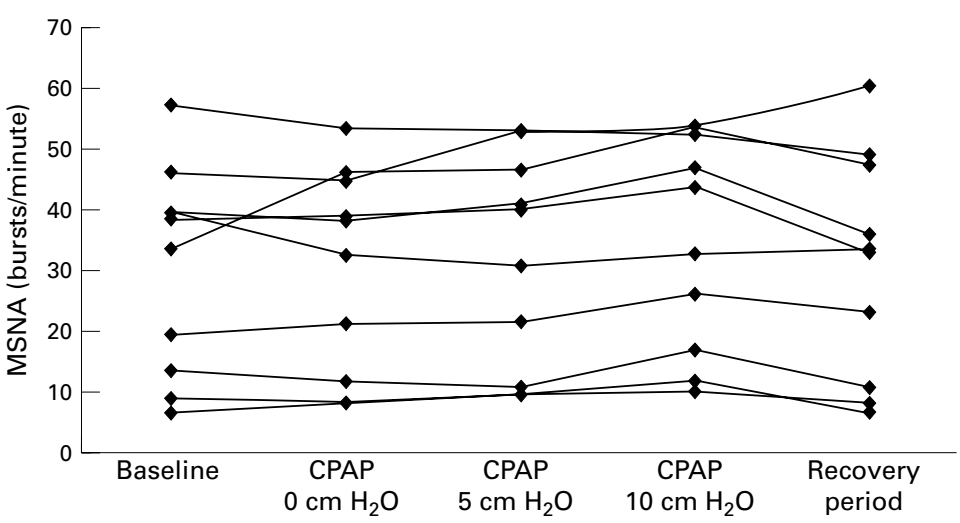

Figure 2 Individual changes of muscle sympathetic nerve activity (MSNA) at baseline, during mask breathing (CPAP $0 \mathrm{~cm} \mathrm{H}_{2} \mathrm{O}$ ), during $C P A P 5$ and $10 \mathrm{~cm} \mathrm{H}_{2} \mathrm{O}$, and during the recovery period in the control subjects. ing CPAP 5 and $10 \mathrm{~cm} \mathrm{H}_{2} \mathrm{O}$ in the patient group and remained stable in the control group compared with mask breathing.

\section{RECOVERY PERIOD}

Muscle sympathetic nerve activity, heart rate, and tidal volume returned to baseline after cessation of CPAP in the patient group. Systolic and diastolic blood pressure (109 (18) $v 114$ (20) $\mathrm{mm} \mathrm{Hg}, \mathrm{p}=0.009$ and 66 (9) $v 68$ (10) $\mathrm{mm} \mathrm{Hg} ; \mathrm{p}=0.08$ ) and oxygen saturation (95.5 (0.3)\% v $96.0(0.2) \%$; $\mathrm{p}=0.02)$ remained at higher levels after cessation of CPAP. Respiratory rate (16 (3) v 14 (3) breaths/min; $\mathrm{p}=0.04)$ and partial pressure of $\mathrm{CO}_{2}(4.80$ (0.53) v $4.67(0.53) \mathrm{kPa} ; \mathrm{p}=0.008)$ were lower during the recovery period compared with baseline.

In the control group, all variables except diastolic blood pressure and partial pressure of $\mathrm{CO}_{2}$ returned to baseline in the recovery period. Diastolic blood pressure was higher, at 78 (3) v 81 (3) $\mathrm{mm} \mathrm{Hg}(\mathrm{p}=0.02)$, and partial pressure of $\mathrm{CO}_{2}$ was lower, at $5.06(0.13) v$ $4.80(0.13) \mathrm{kPa}(\mathrm{p}=0.03)$, in the recovery period compared with baseline.

\section{Discussion}

The main finding of our study is that short term application of CPAP elicits a modest increase in muscle sympathetic nerve activity in both patients with congestive heart failure and healthy control subjects. Mean blood pressure increased simultaneously in both groups while on CPAP.

The most plausible explanation for the increases in sympathetic activity and blood pressure during CPAP is cardiovascular reflex activation of sympathetic outflow. Arterial baroreceptors in the carotid sinus are probably not involved in the sympathetic activation observed during CPAP because arterial blood pressure increased under these conditions. Any rise in arterial blood pressure increases the transmural pressure of the carotid wall ("unloading" of the carotid receptors), which would have triggered a reflex decrease in muscle sympathetic nerve activity rather than the observed increase.

The aortic baroreflex is more likely to have contributed to the CPAP induced sympathetic activation by the following mechanism: the increased intrathoracic pressure during CPAP decreased the transmural pressure in the aortic arch, thus inducing unloading of the aortic receptors and a reflex increase in muscle sympathetic nerve activity.

Cardiopulmonary baroreceptors-located in the right and left atria and ventricles, in the right and left vein-atrial junctions, and in the pulmonary veins - represent another group of baroreceptors regulating sympathetic outflow. ${ }^{20}$ Cardiac preload is considered the main determinant of the activity of these volume sensitive stretch receptors. A reduction in venous return and lowering of cardiac filling pressures by lower body negative pressure results in cardiopulmonary baroreceptor unloading and an increase in muscle sympathetic nerve activity in normal subjects. ${ }^{21}$ It has been shown that 
mechanical ventilation with continuous positive pressure or with positive end expiratory pressure (PEEP) decreases right and left atrial transmural pressures and right and left ventricular end diastolic transmural pressures. ${ }^{22} 23$

We do not know the relative roles of the aortic and the cardiopulmonary baroreflex pathways in the sympathetic activation observed during CPAP. We found an increase in muscle sympathetic nerve activity and mean blood pressure while heart rate remained unchanged during CPAP in both healthy subjects and patients with congestive heart failure. This suggests that the cardiopulmonary baroreceptors play a predominant role in the sympathetic activation observed during CPAP, as unloading of these receptors during lower body negative pressure causes an increase in muscle sympathetic nerve activity without affecting heart rate and mean arterial pressure. ${ }^{20}$ The observed increase in mean arterial blood pressure is probably a sequel of the sympathetic activation during CPAP in our study. The unloading of aortic or cardiopulmonary baroreceptors because of the increased intrathoracic pressure during CPAP may override the potential sympathoinhibitory effect of the increase in arterial blood pressure (and thus in transmural pressure in the carotid arteries). This observation is consistent with the work of Sanders and colleagues, ${ }^{24}$ suggesting that the aortic baroreflex plays a more important role than the carotid baroreflex in the control of sympathetic nerve responses in normal human subjects.

Some alternative mechanisms should be considered when attempting to explain the increases in muscle sympathetic nerve activity and blood pressure during CPAP. Changes in ventilation and blood gases are known to influence the autonomic nervous system. ${ }^{25}{ }^{26} \mathrm{CPAP}$ induces lung inflation and probably stimulates pulmonary vagal afferents, thereby increasing parasympathetic tone and reflexively decreasing sympathetic tone. ${ }^{1326}$ We did not measure end expiratory lung volume or parasympathetic activity, and it is possible that parasympathetic activation with an inhibitory effect on sympathetic activity did occur in our patients and control subjects. However, sympathetic activation caused by diminished baroreceptor discharge seems to override any indirect sympathoinhibitory effect resulting from altered ventilation, so that the net effect is a mild to moderate increase in muscle sympathetic nerve activity in most patients and control subjects.

We observed an increase in oxygen saturation in the patient group and a pronounced fall in end tidal partial pressure of $\mathrm{CO}_{2}$ in both groups while they were on CPAP. These blood gas changes are not likely to have contributed to the CPAP induced increase in sympathetic activity, as hyperoxia is associated either with no change in muscle sympathetic nerve activity or with only a mild decrease, ${ }^{27}{ }^{28}$ and hypocapnia is also likely to induce sympathetic inhibition. ${ }^{29}$

The finding of higher oxygen saturation during CPAP in the patients than in the control subjects is consistent with current concepts of lung function in congestive heart failure. CPAP probably improves the ventilation-perfusion mismatch present in congestive heart failure and therefore improved the oxygen saturation in our patients but not in our control subjects. No change in $\mathrm{PCO}_{2}$ during short term application of CPAP is observed in patients with acute or chronic heart failure. ${ }^{30}{ }^{31}$ We are aware that a systematic underestimation of the end tidal $\mathrm{PCO}_{2}$ during CPAP could have occurred in our investigation. ${ }^{32}$

Finally, it may be suggested that the experimental situation with mask breathing and application of CPAP could have caused mental stress, leading to sympathetic activation. This is not a likely explanation for the observed increase in sympathetic activity in our study, because patients and control subjects were made familiar with the nasal mask and with CPAP before starting the experiment, and breathing with a nasal mask without application of CPAP did not cause any change in sympathetic activity. In addition, heart rate - which is considered as a sensitive indicator of mental stress-did not increase during the experiment. ${ }^{33}$

Consistently with many previous reports, in our present study patients with congestive heart failure had higher levels of sympathetic activity than healthy control subjects matched for age, sex, and body mass index. ${ }^{134}$ Patients were on treatment with diuretics, ACE inhibitors, and glycosides, which may explain the fact that their mean heart rate was not increased in comparison with the controls.

The finding that positive pressure ventilation increases muscle sympathetic nerve activity and blood pressure in healthy subjects is consistent with previous studies. ${ }^{14}{ }^{35}$ However, the application of $10 \mathrm{~cm} \mathrm{H}_{2} 0$ CPAP for 45 minutes had no effect on sympathetic activity or blood pressure in the patients with congestive heart failure reported by Naughton and colleagues. ${ }^{31}$ Although we used similar inclusion criteria in our study, the patients investigated by Naughton and colleagues tended to be more obese (body mass index 27.4 (1.4) kg/ $\mathrm{m}^{2}$ ) and had more restrictive lung function tests (vital capacity 80 (8)\% of predicted), a slightly higher blood pressure (115/ $77 \mathrm{~mm} \mathrm{Hg}$ ), and a higher heart rate (76 (5) beats/min) than our patients, suggesting that the patient populations were not comparable in the two studies.

Two patients had a slight decrease in sympathetic activity during CPAP in our study. These two patients showed a different breathing pattern at baseline, characterised by a high respiratory rate and a low tidal volume which was completely reversed by CPAP. Rapid shallow breathing may reflect increased cardiac filling pressures and pulmonary congestion which could explain the beneficial effect of CPAP on ventilation and sympathetic activity in these two patients. ${ }^{31}$ There is evidence of an altered cardiopulmonary reflex pathway in patients with congestive heart failure and raised pulmonary wedge pressures: isolated deactivation of the cardiopulmonary baroreceptors (during lower body negative pressure) has been shown to cause forearm vasoconstriction in patients with congestive heart failure and normal pulmonary wedge pressures, but a paradoxical 
forearm vasodilatation in a subgroup of patients with congestive heart failure and raised pulmonary wedge pressures. ${ }^{36}$

\section{LIMITATIONS}

A limitation of our study is that we did not measure cardiac output changes during CPAP. In normal subjects, CPAP decreases venous return by increasing the intrathoracic pressure and is thus associated with either no change in cardiac output or with a tendency to decrease the output. ${ }^{77-39}$ However, in congestive heart failure with raised cardiac filling pressure, CPAP may increase cardiac output ${ }^{739}$ either through a decrease in left ventricular transmural pressure (and thereby left ventricular afterload) or through a decrease in sympathoadrenal tone or by vasodilatation. ${ }^{13} 39$

We only investigated the short term effect of CPAP on the sympathetic nervous system. Our results suggest that the favourable haemodynamic effects observed during short term application of CPAP in patients with congestive heart failure $^{7840}$ are not related to a decrease in sympathetic activity, though there may well be beneficial effects on sympathetic activity during long term treatment with nocturnal CPAP, as proposed by Naughton and colleagues. ${ }^{9}$ Other mechanisms are likely to contribute to sympathetic outflow modulations during long term treatment with CPAP — for example, a reduction in Cheyne-Stokes respiration and an improvement in left ventricular performance. Further studies are needed to determine short and long term benefits and the effects of CPAP on the sympathetic nervous system in patients with stable congestive heart failure.

Supported by the Deutsche Forschungsgemeinschaft (DFG, An 260/1-2)

1 Ferguson DW, Berg WJ, Sanders JS. Clinical and hemodynamic correlates of sympathetic nerve activity in norma humans and patients with heart failure: evidence from direct microneurographic recordings. I Am Coll Cardiol 1990;16:1125-34.

2 Floras JS. Clinical aspects of sympathetic activation and parasympathetic withdrawal in heart failure. $f \mathrm{Am} \mathrm{Coll} \mathrm{Car}$ diol 1993;22:72-84a.

3 Lanfranchi PA, Braghiroli A, Bosimini E, et al. Prognostic value of Cheyne-Stokes respiration in chronic heart failure. Circulation 1999;99:1435-40.

4 Andreas S, Clemens C, Sandholzer H, et al. Improvement of exercise capacity with treatment of Cheyne-Stokes respiration in patients with congestive heart failure. $\mathcal{F} \mathrm{Am}$ Coll Cardiol 1996;27:1486-90.

5 Bersten AD, Holt AW, Vedig A. Treatment of severe cardiogenic pulmonary edema with continuous positive airway genic pulmonary edema with continuous positive airway
pressure delivered by a face mask. $N$ Engl f Med 1991;325: pressure celi 1825 .

6 Baratz DM, Westbrook PR, Shah PK. Effect of continuous positive airway pressure on cardiac output and oxygen delivery in patients with congestive heart failure. Chest 1992;102:1397-407.

7 Bradley TD, Holloway RM, McLaughlin PR, et al. Cardiac output response to continuous positive airway pressure in congestive heart failure. Am Rev Respir Dis 1992;145:37782.

8 De Hoyos A, Liu PP, Benard DC, et al. Haemodynamic effects of continuous positive airway pressure in humans with normal and impaired left ventricular function. $\mathrm{Clin} \mathrm{Sci}$ 1995;88:173-8.

9 Naughton MT, Liu PP, Bernard DC, et al. Treatment of congestive heart failure and Cheyne-Stokes respiration during sleep by continuous positive airway pressure. Am $\mathcal{F}$ Respir Crit Care Med 1995;151:92-7.

10 Buckle P, Millar T, Kryger M. The effect of short-term nasal CPAP on Cheyne-Stokes respiration in congestive heart CPAP on Cheyne-Stokes respir
failure. Chest 1992;102:31-5.

11 Davies RJ, Harrington KJ, Ormerod OJ, et al. Nasal continuous positive airway pressure in chronic heart failure with sleep-disordered breathing. Am Rev Respir Dis 1993; 147:630-4

12 Liston R, Deegan PC, McCreery C, et al. Haemodynamic effects of nasal continuous positive airway pressure in severe congestive heart failure. Eur Respir f 1995;8:430-5.

13 Butler GC, Naughton MT, Rahman MA, et al. Continuous positive airway pressure increases heart rate variability in

14 Sellden H, Sjovall H, Wallin BG, et al. Changes in muscle sympathetic nerve activity, venous plasma catecholamines, and calf vascular resistance during mechanical ventilation with PEEP in humans. Anesthesiology 1989;70:243-50.

15 Delius W, Hagbarth KE, Hongell A, et al. General characteristics of sympathetic activity in human muscle nerves. Acta Physiol Scand 1972;84:65-81.

16 Vallbo AB, Hagbarth KE, Torebjork HE, et al. Somatosensory, proprioceptive and sympathetic activity in human peripheral nerves. Physiol Rev 1979;59:919-57.

17 Rea RF, Grossman E, Goldstein DS. Relation between sympathetic nerve activity and norepinephrine spillover in humans [abstract]. Clin Res 1990;38:828A.

18 Carry P-Y, Baconnier P, Eberhard A, et al. Evaluation of respiratory inductive plethysmography. Accuracy for analysis of respiratory waveforms. Chest 1997;111:910-15.

19 Cummin ARC, Alison J, Jacobi MS, et al. Ventilatory sensitivity to inhaled carbon dioxide around the control point during exercise. Clin Sci 1986;71:17-22.

20 Mitchell JH, Victor RG. Neural control of the cardiovascular system: insights from muscle sympathetic nerve recordings in humans. Med Sci Sports Exerc 1996;28:S60-9.

21 Sundlöf G, Wallin BG. Effect of lower body negative pressure on human muscle nerve sympathetic activity. $\mathcal{F}$ Physiol (Lond) 1978;278:525-32.

22 Fewell JE, Abendschein DR, Carlson J, et al. Mechanism of decreased right and left ventricular end-diastolic volumes during continuous positive-pressure ventilation in dogs. Circ Res 1980;47:467-72.

23 Qvist J, Pontoppidan H, Wilson RS, et al. Hemodynamic responses to mechanical ventilation with PEEP: the effect of hypervolemia. Anesthesiology 1975;42:45-55.

24 Sanders JS, Ferguson DW, Mark AL. Arterial baroreflex control of sympathetic nerve activity during elevation of blood pressure in normal man: dominance of aortic baroreflexes. Circulation 1988;77:279-88.

25 Somers VK, Mark AL, Zavala DC, et al. Contrasting effects of hypoxia and hypercapnia on ventilation and sympathetic activity in humans. F Appl Physiol 1989;67:2101-6.

26 Seals DR, Suwarno O, Dempsey JA. Influence of lung volume on sympathetic nerve activity in normal humans. Circ Res 1990;67:130-41.

27 Haque WA, Boehmer J, Clemson BS, et al. Hemodynamic effects of supplemental oxygen administration in congestive heart failure. 7 Am Coll Cardiol 1996;27:353-7.

28 Seals DR, Johnson DG, Fregosi RF. Hyperoxia lowers sympathetic activity at rest but not during exercise in humans. Am F Physiol 1991;260:R873-8.

29 Moster WG, Reier CE, Gardier RW, et al. Cardiac output and postganglionic sympathetic activity during acute respiratory alkalosis. Anesthesiology 1969;31:29-35.

30 Lenique F, Habis M, Lofaso F, et al. Ventilatory and hemodynamic effects of continuous positive airway pressure in left heart failure. Am f Respir Crit Care Med 1997;155:500-5.

31 Naughton MT, Floras JS, Rahman MA, et al. Respiratory correlates of muscle sympathetic nerve activity in heart failure. Clin Sci 1998;89:277-85.

32 Parreira VF, Delguste P, Delaere S, et al. Does end-tidal CO pressure accurately reflect arterial $\mathrm{CO}_{2}$ pressure in normal subjects during spontaneous breathing and nasal intermittent positive pressure ventilation? [abstract] Eur Resp $\mathcal{F}$ 1998;12(S28):A1553.

33 Hjemdahl P, Freyschuss U, Juhlin-Dannfelt A, et al. Differentiated sympathetic activation during mental stress evoked by the Stroop test. Acta Physiol Scand 1984;527: S25-9.

34 Leimbach WN, Wallin BG, Victor RG, et al. Direct evidence from intraneural recordings for increased central sympathetic outflow in patients with heart failure. Circulation 1986;73:913-19.

35 Tanaka S, Sagawa S, Miki K, et al. Changes in muscle sympathetic nerve activity and renal function during positivepressure breathing in humans. Am $\mathcal{F}$ Physiol 1994;266: R1220-8.

36 Nishian K, Kawashima S, Iwasaki T. Paradoxical forearm vasodilation and haemodynamic improvement during cardiopulmonary baroreceptor unloading in patients with congestive heart failure. Clin Sci 1993;84:271-80.

37 Leech JA, Ascah KJ. Hemodynamic effects of nasal CPAP examined by Doppler echocardiography. Chest 1991;99: 323-6.

38 Montner PK, Greene ER, Murata GH, et al. Hemodynamic effects of nasal and face mask continuous positive airway pressure. Am f Respir Crit Care Med 1994;149:1614-18.

39 Scharf SM, Chen L, Slamowitz D, et al. Effects of continuous positive airway pressure on cardiac output and plasma norepinephrine in sedated pigs. $\mathcal{F}$ Crit Care 1996;11:57-64.

40 Naughton MT, Rahman MA, Hara K, et al. Effect of continuous positive airway pressure on intrathoracic and
left ventricular transmural pressures in patients with congestive heart failure. Circulation 1995;91:1725-31. 